\title{
Destekli Sıvı Membranların Hazırlanması, Karakterizasyonu ve Ayırma İșlemlerinde Kullanılması
}

\author{
Figen ILGAZ1 ${ }^{1}$ Esengül KIR*2, Tuğba SARDOHAN KöSEOĞLU³ ${ }^{3}$ Bülent DEDE ${ }^{4}$
}

\author{
1,2,4Süleyman Demirel Üniversitesi, Fen Edebiyat Fakültesi, Kimya Bölümü, 32260, Isparta, Türkiye \\ 1 (ORCID: https://orcid.org/0000-0002-9808-485X) \\ ${ }^{2}$ (ORCID: https://orcid.org/0000-0002-6641-3444) \\ ${ }^{4}$ (ORCID: https://orcid.org/0000-0003-1416-7373)
}

3Isparta Uygulamalı Bilimler Üniversitesi, Teknoloji Fakültesi, Biyomedikal Mühendisliği Bölümü, 32260, Isparta, Türkiye

${ }^{3}$ (ORCID: https://orcid.org/0000-0002-0707-9191)

(Alınıș / Received: 05.03.2019, Kabul / Accepted: 16.04.2019, Online Yayınlanma / Published Online: 25.04.2019)

Anahtar Kelimeler Aminoketooksim, Destekli sıvı membran, Fe(III),

Karakterizasyon,

$\mathrm{Ni}(\mathrm{II})$,

TOPO
Özet: $\mathrm{Bu}$ çalışmada, taşıyıcı olarak farklı fonksiyonel gruplara sahip ve her biri N$\mathrm{N}$ - dimetil formamit organik fazında çözünen trioktilfosfin oksit (TOPO) ve N(furan-2-ilmetil)-N'-hidroksi-2-okso-2-(4-fenilfenil)-etenimidamit (BKOF) bileşikleri kullanılarak iki yeni tür destekli sıvı membran (DSM) hazırlanmıștır. Destek tabakası olarak hidrofobik poliviniliden florür (PVDF) ve poliamit mikroporöz membranlar kullanılmıştır. Hazırlanan membranlar taramalı elektron mikroskobu (SEM), enerji dağılım X-ray spektroskopisi (SEM-EDS), atomik güç mikroskobu (AFM), fourier dönüşümlü infrared spektroskopisi (FTIR) ve termogravimetrik analiz (TGA) gibi analitik metotlar kullanılarak karakterize edilmiştir. Karakterizasyon işlemleri, hazırlanan DSM'lerin yüzey morfolojilerinin PVDF ve poliamit destek tabakalarına kıyasla farklı olması, bu membranların yeni tür olduklarını doğrulamaktadır. Hazırlanan DSM'lerin performası, donnan diyaliz metodu kullanılarak sulu çözelti ortamından $\mathrm{Ni}(\mathrm{II})$ ve $\mathrm{Fe}(\mathrm{III})$ iyonlarının uzaklaştırma deneylerinde değerlendirilmiştir. En yüksek akı değerleri besleme fazı konsantrasyonu $1,0 \times 10^{-1} \mathrm{M} \mathrm{NiCl}_{2} \cdot 6 \mathrm{H}_{2} \mathrm{O}$ veya $1,0 \times 10^{-1} \mathrm{M} \mathrm{Fe}\left(\mathrm{NO}_{3}\right)_{3} \cdot 9 \mathrm{H}_{2} \mathrm{O}$ ve alıcl faz konsantrasyonları $1,0 \times 10^{-1} \mathrm{M} \mathrm{HCl}$ veya $1,0 \times 10^{-1} \mathrm{M} \mathrm{HNO}_{3}$ olduğu zaman elde edilmiştir.

\section{Preparation of Supported Liquid Membranes, Characterization and Using in Separation Processes}

\section{Keywords}

Aminoketooxime,

Characterization,

Fe(III),

$\mathrm{Ni}(\mathrm{II})$,

Supported liquid membrane, TOPO

\begin{abstract}
In this study, two novel supported liquid membranes (SLMs) was developed by using Trioctylphosphine oxide (TOPO) and N-(furane-2-iylmethyl)N'-hydroxy-2-oxo-2-(4-phenylphenyl) eteneimideamide (BKOF) as a carrier that have different functional groups, each dissolved in the organic phase $\mathrm{N}$-N-dimethyl formamide. Hydrophobic polyvinylidene fluoride (PVDF) and polyamide microporous membranes were used as support to prepare these membranes. Developed membranes were characterized with several analytical methods, including scanning electron microscopy (SEM), energy dispersive X-ray spectroscopy (SEM-EDS), Fourier transform infrared spectroscopy (FTIR), atomic force microscopy (AFM), and thermal gravimetric analysis (TGA). Characterization processes confirm the novelty of membranes due to different surface morphologies of prepared SLMs, compared to the PVDF and polyamide supports. Performance of prepared SLMs were evaluated by rejection tests for Ni(II) and Fe(III)) from aqueous solutions by using Donnan dialysis method. The highest flux values were obtained when the feed phase concentration of $1.0 \times 10^{-1} \mathrm{M} \mathrm{NiCl}_{2} \cdot 6 \mathrm{H}_{2} \mathrm{O}$ or $1.0 \times 10^{-1} \mathrm{M} \mathrm{Fe}\left(\mathrm{NO}_{3}\right)_{3} .9 \mathrm{H}_{2} \mathrm{O}$, the strip phase concentration of $1.0 \times 10^{-1} \mathrm{M} \mathrm{HCl}$ or $1.0 \times 10^{-1} \mathrm{M} \mathrm{HNO}_{3}$, respectively.
\end{abstract}




\section{Giriş}

Membranlar kullanılarak yapılan ayırma teknolojileri, son yıllarda hızla büyüyen bir alan olarak gelişmektedir. Membran teknolojisi, diğer teknolojiler ile kıyaslandığında düşük enerji gereksinimi, düşük maliyet ve çalıştırma imkanları ve çevre dostu olması nedeni ile birçok avantajlara sahiptir [1]. Bu teknolojiler arasinda, ters osmoz, nanofiltrasyon, ultrafiltrasyon, mikrofiltrasyon, elektrodiyaliz ve donnan diyaliz gibi teknikler çok kullanılmaktadır [2]. Membran uygulamalarında, polimerik membranlar ve sivı membranlar, proses verimliliği ve maliyet açısından oldukça fazla kullanılmaktadır. Sıvı membran prosesleri diğer geleneksel ayırma metotlarına göre yüksek taşıma oranı ve iyi seçicilikleri nedeni ile bazı avantajlara sahiptir [3].

Sıvı membranların, yığın (BLM), emülsiyon (ELM) ve destekli sıvı membranlar (DSM) olarak çeşitleri mevcuttur. Son zamanlarda, bu membranlar arasinda olan destekli sıvı membranlar, sulu çözeltilerden bazı metalleri geri kazanmak ve uzaklaştırmak için geniş çapta kullanılmaktadır [4-6]. Bu membranların hazırlanmasinda destek membran materyali olarak, poli(vinilidenflorür) (PVDF), polipropilen (PP), polietilen (PE) ve polisülfon (PS) gibi polimerler iyi mekaniksel, kimyasal ve ısı direnci performansları nedeniyle tercih edilmektedir [2]. Organik bir çözücü içinde çözünen ve iyon taşıyıcı özelliğine sahip bir ligand, seçilen destek tabakası üzerine emdirilerek DSM'ler hazırlanır [7]. DSM'lerin hazırlanmasında kullanılan iyon taşıyıcıların seçimi seçicilik açısından oldukça önemlidir. Bu amaçla, çoğunlukla, oksimler, taç eterler, kaliksarenler, azo bileşikleri, Schiff bazları, fosfinler gibi bileşiklerin yanı sıra ticari ligandlar da kullanılmaktadır [8-12].

Oksimler, aldehit ve ketonların hidroksilaminle reaksiyonları sonunda oluşan, yapısında karbon-azot çifte bağı taşıyan bileşiklerdir. Genel formülleri R1R2C=NOH veya $\mathrm{RCH}=\mathrm{NOH}$ șeklindedir. [13].

Oksim bileşikleri şelat oluşturma özelliği nedeni ile değerli metallerin geri kazanılmasinda kullanılmaktadır. Ayrıca, bu bileşiklerin biyolojik olarak parçalanabilme ve oksijen tutma özellikleri nedeni ile tıp alanında ve biyoorganik sistemlerde yaygin kullanımları da mevcuttur. [14].

Bazı ağır metaller sularda izin verilen konsantrasyonları aştıkları zaman toksik olabilmektedir, bu nedenle uygun metotlar kullanılarak ortamdan uzaklaştırılmaları gerekir. Membranların kullanıldığı Donnan diyaliz metodu da bu metotların en ekonomik ve verimli olanlarından biridir [15-16].
Bu çalışmada, ticari bir ligand olan trioktilfosfin oksit (TOPO) ve laboratuvarda sentezlenen bir oksim bileşiği olan $\mathrm{N}$-(furan-2-ilmetil)-N'-hidroksi-2-okso2-(4-fenilfenil)etenimideamit (BKOF) bileşikleri kullanılarak destekli sıvı membranlar hazırlanmıştır. Hazırlanan destekli sıvı membranlar, Taramalı Elektron Mikroskobu (SEM), Fourier Dönüşümlü İnfrared Spektroskopisi (FTIR), Atomik Güç Mikroskopu (AFM) ve Termal Gravimetrik Analiz (TGA) teknikleri kullanılarak karakterize edilmiştir. Karakterizasyon ișlemlerinden sonra, destekli sivı membranlar sulu çözelti ortamından Fe(III) ve Ni(II) iyonlarının uzaklaștırılması deneylerinde kullanılmıştır.

\section{Materyal ve Metot}

\subsection{Kullanılan kimyasal madde ve malzemeler}

Kullanılan tüm kimyasal maddeler $\left(\mathrm{NiCl}_{2} \cdot 6 \mathrm{H}_{2} \mathrm{O}\right.$, $\mathrm{Fe}\left(\mathrm{NO}_{3}\right)_{3} .9 \mathrm{H}_{2} \mathrm{O}$, 1-metil-2-prolidon, N-Ndimetilformamit, $\mathrm{HCl}, \mathrm{HNO}_{3}$, TOPO) analitik saflıkta ve Merck, Fluka ve Carlo Erba firmalarından temin edilmiștir. BKOF bileșiği literatüre göre sentezlenerek kullanılmıştır [17]. Hidrofobik PVDF Millipore, Poliamit ise Whatman firmasından satın alınmıştır. Kullanılan membranların özellikleri Tablo 1'de verilmiştir.

Tablo 1. Deneylerde kullanılan destek tabakalarının yapı özellikleri

\begin{tabular}{lllll}
\hline $\begin{array}{l}\text { Destek } \\
\text { tabakaları }\end{array}$ & $\begin{array}{l}\text { Gözenek } \\
\text { Çapı } \\
(\mu \mathrm{m})\end{array}$ & $\begin{array}{l}\text { Kalınlığı } \\
(\mu \mathrm{m})\end{array}$ & $\begin{array}{l}\text { Türü } \\
\text { (Islanabilirlik) }\end{array}$ & Geçirgenlik \\
\hline PVDF & 0,22 & 125 & Hidrofobik & $\% 70$ \\
\hline Poliamit & 0,45 & 115 & Hidrofilik & - \\
\hline
\end{tabular}

Deneylerde kullanılan taşıyıcıların molekül formülleri de aşağıda gösterilmiştir (Tablo 2-3).

Tablo 2. T1 numaralı taşıyıcının özellikleri

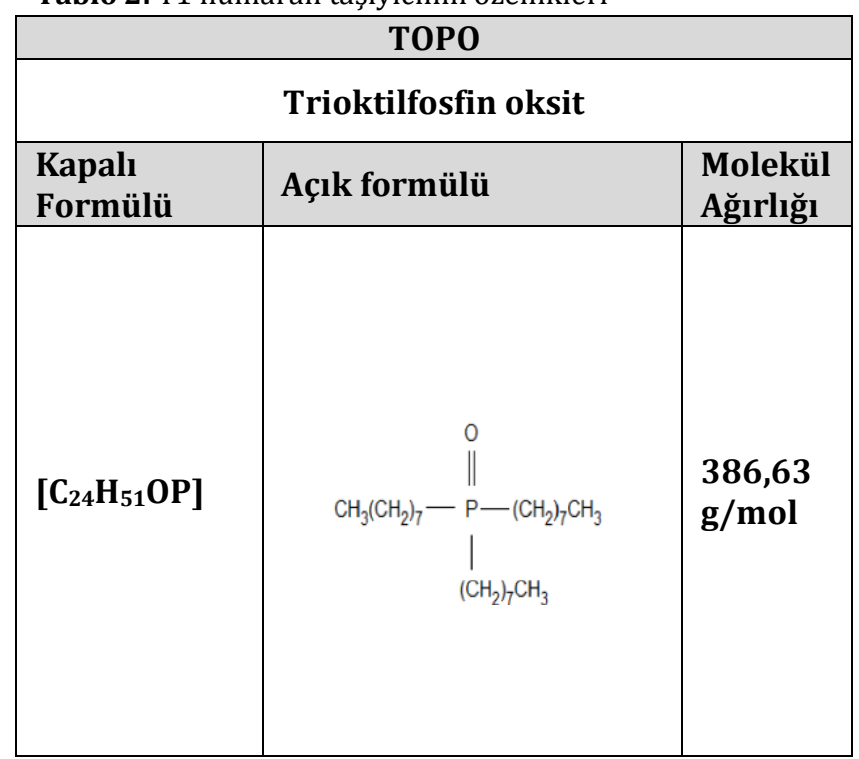


Tablo 3. T2 numaralı tașıyıcının özelikleri

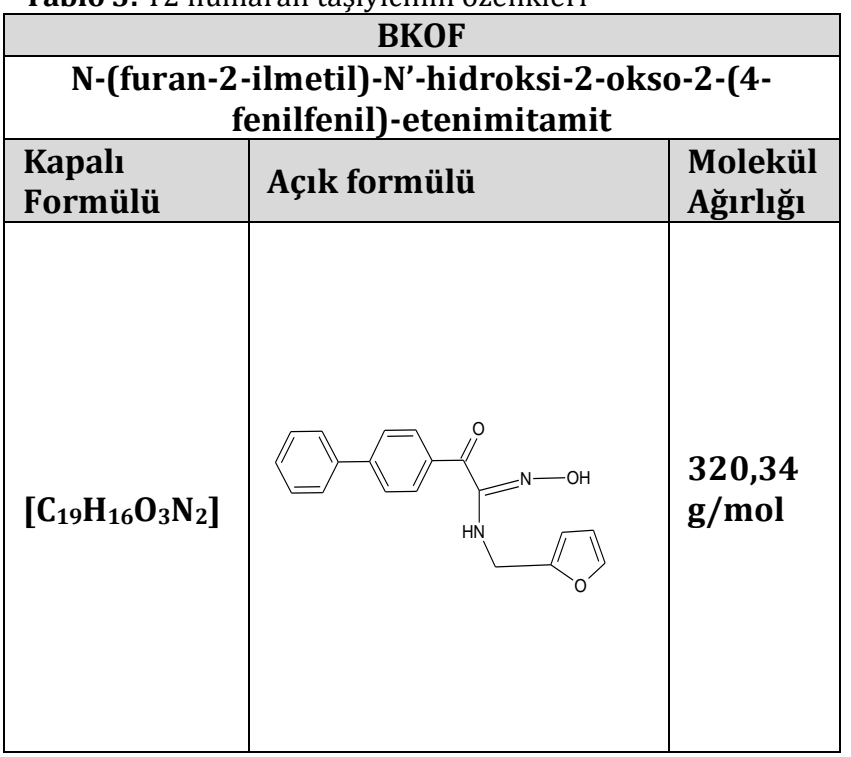

\subsection{Kullanılan cihazlar}

Destekli sıvı membranların morfolojik yapıları SEM, SEM-EDS ve AFM cihazları kullanılarak incelenmiștir. Membranların yapısal olarak karakterizasyonu TGA ile incelenirken, spektroskopik olarak incelenmesi ise FTIR cihazı ile gerçekleştirilmiştir. FTIR ölçümleri Perkin Elmer Spectrum BX cihazı ile, SEM ölçümleri FEI Quanta FEG 250 model taramalı elektron mikroskobu ile, AFM ölçümleri Nanomagneticsez AFM cihazı ile ve termal gravimetrik analizleri de Perkin Elmer Diamond TGA Termal Analiz cihazı ile gerçekleştirilmiştir.

Belirli zaman aralıklarında besleme fazından alıcı faza taşınan iyonların derişim tayini, Ni(II) tayini için 231,604 nm, Fe(III) tayini için 238,204 nm dalga boyunda EPA 6010 metoduna uygun olarak PerkinElmer marka OPTIMA 5300 DV model optik emisyon spektroskopisi (ICP-OES) ile yapılmıştır.

\subsection{Donnan diyaliz ünitesi}

Donnan diyaliz ünitesi, teflondan özel olarak dizayn edilmiş iki bölmeli bir düzenektir. Her iki bölme 45 mL'lik bir kapasiteye sahiptir. Bölmelerdeki çözeltilerin karışımı, manyetik karıştırıcı üzerinde, çözelti içerisine atılan manyetik balıklar sayesinde gerçekleştirilmektedir. Deney düzeneğinde destekli sıvı membranlar kullanılmıştır. Bölmeler arasına koyulacak olan membran, sızıntıyı önlemek amacıyla halkalar ve contalar kullanılarak sıkıştırılmıştır. Böylece düzeneğin sızdırma ihtimali ortadan kaldırılmıştır. Kullanılan ünitenin şekli aşağıda verilmiştir (Şekil 1).

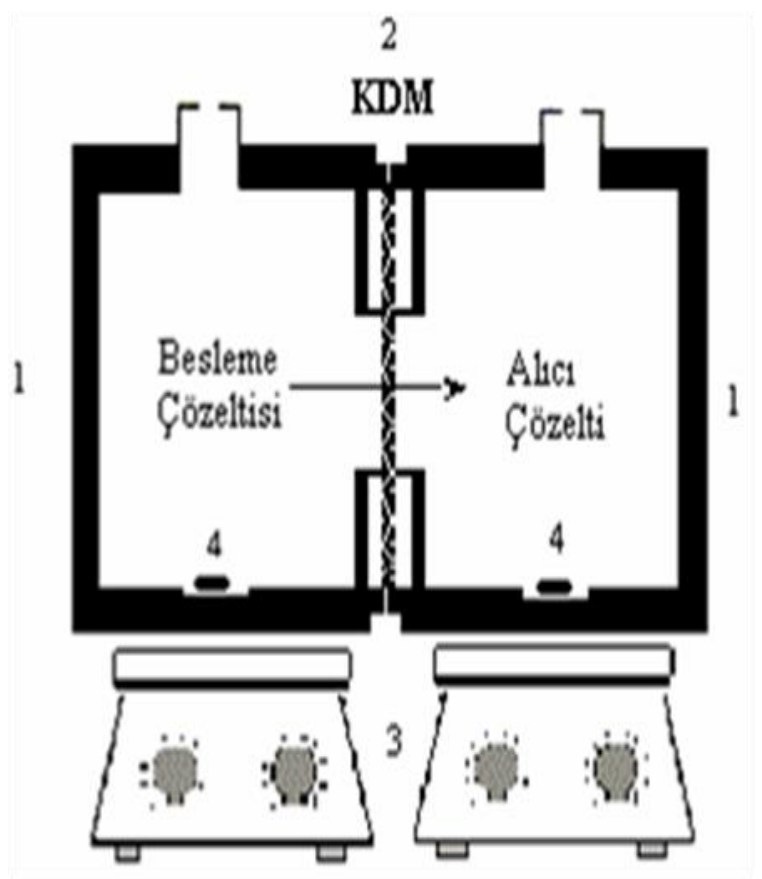

Şekil 1. Donnan diyaliz sistemi

\subsection{Donnan diyaliz mekanizması}

Mekanizma oldukça basittir. Bir donnan diyaliz ünitesinde ara bölmeye iyon geçirgen membran olarak katyon ya da anyon değiştirici membran yerleştirilir. Membran sabit bir yüke ve hareketli bir karşıt yüke sahiptir. Membranın sol tarafında besleme çözeltisi adı verilen ayırmak istenilen iyonlardan oluşan bir çözelti, sağ tarafında ise alıcı çözelti adı verilen ayırmak istenilen iyonların geçtiğ bir çözelti bulunmaktadır.

Bir katyon ayırdığımızı düşünürsek, besleme çözeltisindeki katyon, sabit pozitif yük ile birleştirilmiş hareketli membran katyonu ile yarışır. Önce katyon membrana bağlanır, sonra donnan potansiyel etkisi ile membrandan geçerek alıcı tarafa taşınır. Böylece membran içindeki hareketli iyonların toplam sayısı her zaman sınırlıdır. Burada, membran yüzeyi ve çözelti arasında hem farklı değerlikteki iyonların olmasından hem de derişim etkisinden dolayı bir potansiyel fark oluşmaktadır. Donnan denge şartları sağlanana kadar bu taşıma ve potansiyel farklılık devam etmektedir. Besleme ve alıcı çözeltileri arasında ayırma, kayıp olmadan yani çevreden yalıtılmış kapalı bir sistemde yapılmaktadır. $\mathrm{Bu}$ proseste, katyonlar negatif yüklü katyon değiştirici membran içinden, anyonlar da pozitif yüklü anyon değiştirici membran içinden kolaylıkla taşınırlar. Katyon ve anyon değiştirici membranlardan iyonların taşınmasının genel gösterimi ise, Şekil 2' de verilmiştir. 


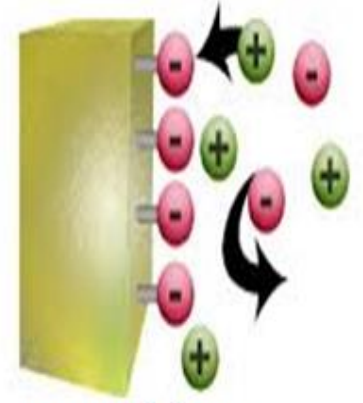

Katyon değişim mekanizması

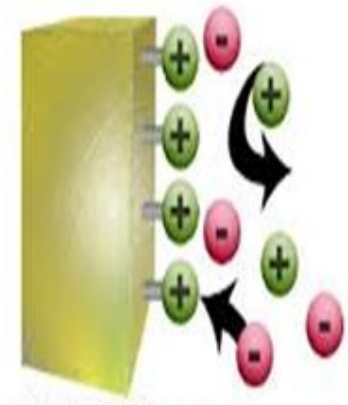

Anyon değişim mekanizması
Şekil 2. Donnan diyaliz çalışma prensibi

\subsection{Yöntem}

\subsubsection{Destekli sıvı membranların hazırlanması}

Destekli sıvı membranların hazırlanmasında destek tabakası olarak, Tablo 4'te verilen polimer destek tabakaları kullanılmıştır. Taşıyıcı olarak, farklı yapılardaki TOPO ve BKOF maddeleri kullanılmıştır. Çözücü olarak dimetilformamit kullanılmıștır. Taşıyıcılar, 0,5-1 g arasında tartılarak organik çözücülerde çözülmüș ve polimer destek tabakası üzerine dökülmüştür. Daha sonra membran, çözücünün uzaklaşması ve taşıyıcının polimer destek tabakasına immobilize olması için 1 gün oda sıcaklığında bekletilmiștir. Son olarak membran saf su içerisine alınmış ve kullanıma hazır hale getirilmiştir. Hazırlanan destekli sıvı membranlar aşağıdaki tabloda verilmiştir.

Tablo 4. Hazırlanan destekli sıvı membranlar

\begin{tabular}{|l|l|l|l|}
\hline $\begin{array}{l}\text { Membran } \\
\text { Kod }\end{array}$ & Çözücü & Taşıyıcı & $\begin{array}{l}\text { Destek } \\
\text { Tabakası }\end{array}$ \\
\hline T1-PA-DSM & N,N-Dimetilformamit & TOPO & Poliamit \\
\hline T2-HB-DSM & N,N-Dimetilformamit & BKOF & $\begin{array}{l}\text { Hidrofob } \\
\text { PVDF }\end{array}$ \\
\hline
\end{tabular}

\subsubsection{Donnan diyaliz deneyleri}

Laboratuvar ortaminda sentezlenen BKOF taşıyıcısının literatür taramaları kapsamında Ni(II) iyonuna karşı seçiciliği tespit edilerek donnan diyaliz çalışmaları gerçekleştirilmiştir [17]. Ticari taşıyıcı TOPO maddesinin ise Fe(III) iyonuna karşı ilgisi literatürlerden tespit edilmiş ve donnan diyaliz deneylerinde kullanılmıştır [18]. Deneysel parametre olarak besleme faz konsantrasyon çalışması yapılmıștır.

\subsubsection{Besleme faz konsantrasyon çalışmaları}

Ayırmaya besleme faz konsantrasyon etkisi çalışmaları kapsamında, hazırlanan her iki destekli sıvı membran ile deneyler gerçekleştirilmiştir.
Donnan diyaliz şartlarında BKOF taşıyıcısı içeren membranlar için besleme çözeltisi olarak;

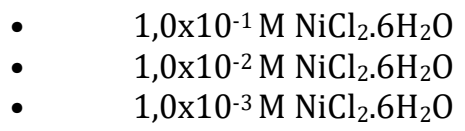

çözeltileri kullanılmıştır.

Donnan diyaliz şartlarında TOPO taşıyıcısı içeren membranlar için besleme çözeltisi olarak;

$\begin{array}{ll}- & 1,0 \times 10^{-1} \mathrm{M} \mathrm{Fe}\left(\mathrm{NO}_{3}\right)_{3} .9 \mathrm{H}_{2} \mathrm{O} \\ \text { - } & 1,0 \times 10^{-2} \mathrm{M} \mathrm{Fe}\left(\mathrm{NO}_{3}\right)_{3} .9 \mathrm{H}_{2} \mathrm{O} \\ & 1,0 \times 10^{-3} \mathrm{M} \mathrm{Fe}\left(\mathrm{NO}_{3}\right)_{3} .9 \mathrm{H}_{2} \mathrm{O}\end{array}$

çözeltileri kullanılmıştır.

Alıcı faz olarak iyonların taşındı̆̆ bölmede bütün membranlar için $1 \times 10^{-1} \mathrm{M} \mathrm{HCl} \mathrm{çözeltisi} \mathrm{kullanılmıştır.}$ 3 saat sonunda alıcı faz bölmesinden $1 \mathrm{~mL}$ alınarak 25 mL'ye tamamlanmış ve çözeltideki iyonların derişimi tayin edilmiştir.

\section{Sonuçlar ve Tartışma}

Çalışma kapsamında iki farklı tür destekli sıvı membran hazırlanmıștır. Bu membranlar sırası ile; T1-PA-DSM ve T2-HB-DSM olarak kodlanmıştır. Hazılanan membranların öncelikle karakterizasyonu SEM, SEM-EDS, FT-IR, AFM ve TGA analizleri kullanılarak yapılmıştır.

\subsection{Membranların SEM görüntüleri}

Şekil 3'te orijinal destek tabakalarının ve hazırlanan destekli sıvı membranların SEM görüntüleri verilmiştir.
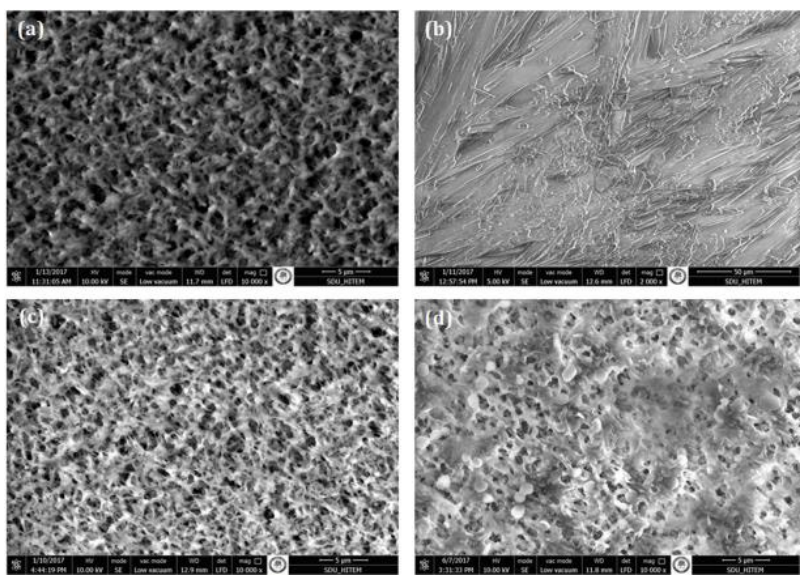

Şekil 3. Membranların SEM görüntüleri (a) Orijinal Poliamit destek tabakası ( $5 \mu \mathrm{m}$ ), (b) T1-PA-DSM membran $(50 \mu \mathrm{m})$, (c) Orijinal hidrofob PVDF destek tabakası $(5 \mu \mathrm{m})$, (d) T2-HB-DSM membran (5 $\mu \mathrm{m})$ 
Şekil 3'te verilen SEM görüntülerinden de görüldüğü gibi orijinal destek tabakaları ile taşıyıcı içeren (T1 ve T2) destekli sıvı membranların morfolojilerinde farklılıklar gözlemlenmiştir. Membran yüzeyleri arasındaki bu farklılı taşıyıcıların destek tabakalarına immobilize olduğunu göstermektedir. Destek tabakalarının gözenek yapısınının değişmesi hazırlanan membranların yeni tür membranlar olduğunu kanıtlamaktadır.

\subsection{Membranların SEM-EDS sonuçları}

Şekil 4-7'de orijinal destek tabakalarının ve hazırlanan destekli sıvı membranların SEM-EDS grafikleri verilmiştir. Ayrıca, Tablo 5-8'de ağırlık özellikleri verilmiştir.

Şekil 4'te orijinal hidrofob PVDF destek tabakasının SEM-EDS grafiği görülmektedir. PVDF, $\left(\mathrm{C}_{2} \mathrm{H}_{2} \mathrm{~F}_{2}\right)_{\mathrm{n}}$ genel formülüne sahiptir. Şekil 4'te verilen SEM-EDS grafiği ve Tablo 5'te verilen atom miktarlarından da görüldüğü gibi PVDF için yapı doğrulanmaktadır.

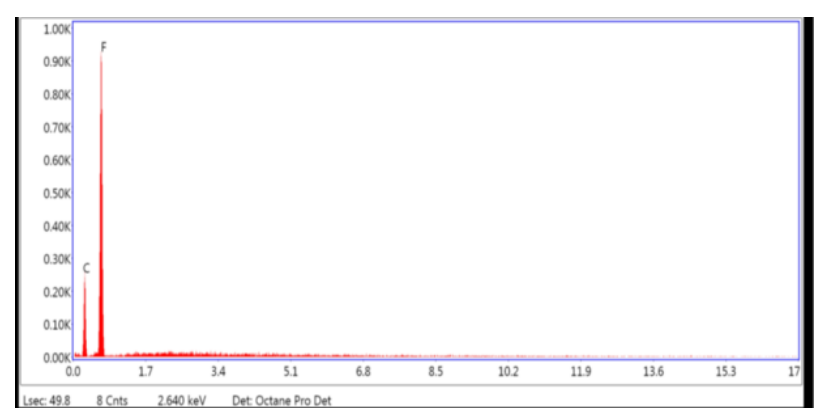

Şekil 4. Orijinal hidrofob PVDF destek tabakası SEM-EDS grafiği

Tablo 5. Orijinal hidrofob PVDF destek tabakasının atom miktarları

\begin{tabular}{lll}
\hline Element & \% A ğırlık & \% Atomik \\
\hline $\mathrm{C}$ & 41,37 & 52,74 \\
\hline $\mathrm{F}$ & 58,63 & 47,26 \\
\hline
\end{tabular}

Şekil 5'te hidrofob PVDF destek tabakası üzerine T2 taşıyıcısı olan BKOF bileşiğinin immobilize edildikten sonraki SEM-EDS grafiği verilmiştir. Orijinal hidrofob PVDF destek tabakasında olmayan oksijenin \% 5,67 oranında yapıya girdiği, Tablo 6'da açıkça görülmektedir.

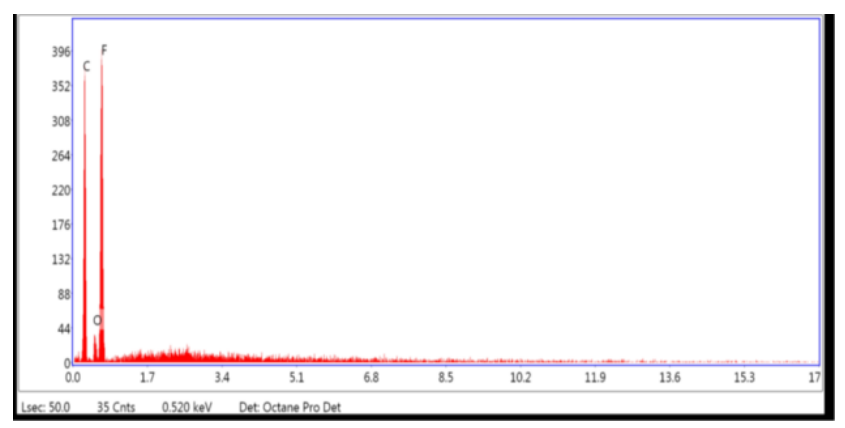

Şekil 5. T2-HB-DSM'ın SEM-EDS grafiği
Tablo 6. T2-HB-DSM'ın atom miktarları

\begin{tabular}{lll}
\hline Element & \% Ağırlık & \% Atomik \\
\hline $\mathrm{C}$ & 54,63 & 65,04 \\
\hline $\mathrm{F}$ & 39,70 & 29,88 \\
\hline $\mathrm{O}$ & 5,67 & 5,07 \\
\hline
\end{tabular}

Orijinal poliamit destek tabakasının SEM-EDS grafiği Şekil 6'da verilmiştir. Poliamit, $\mathrm{C}_{12} \mathrm{H}_{25} \mathrm{~N}_{2} \mathrm{O}_{4}$-genel formülüne sahiptir. Şekil 6'da verilen SEM-EDS grafiği ve Tablo 7'de verilen atom miktarlarından da görüldüğü gibi poliamit için yapı doğrulanmaktadır.

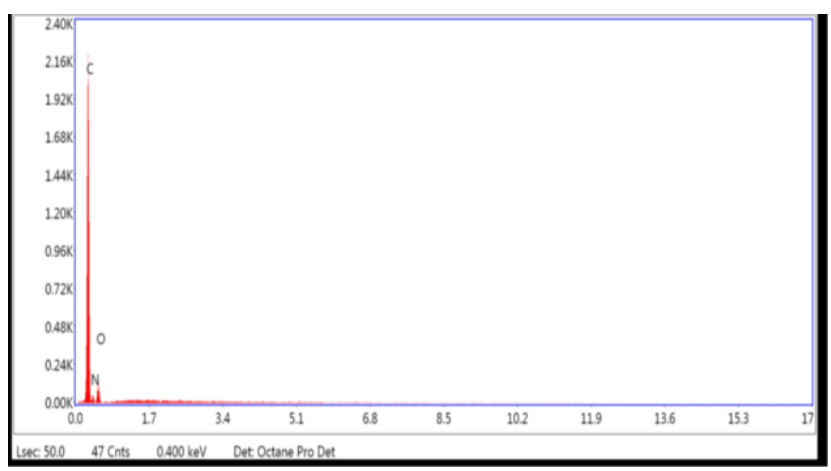

Şekil 6. Orijinal poliamit destek tabakası SEM-EDS grafiği

Tablo 7. Orijinal poliamit destek tabakasının atom miktarları

\begin{tabular}{lll}
\hline Element & \% A Ăırlık & \% Atomik \\
\hline $\mathrm{C}$ & 69,21 & 73,57 \\
\hline $\mathrm{N}$ & 16,33 & 14,89 \\
\hline $\mathrm{O}$ & 14,46 & 11,54 \\
\hline
\end{tabular}

Şekil 7'de poliamit destek tabakası üzerine T1 taşıyıcısı olan TOPO bileșiğinin immobilize edildikten sonraki SEM-EDS grafiği verilmiștir. Orijinal poliamit destek tabakasında olmayan fosforun \% 0,66 oranında yapıya girdiği, Tablo 8'de açıkça görülmektedir.

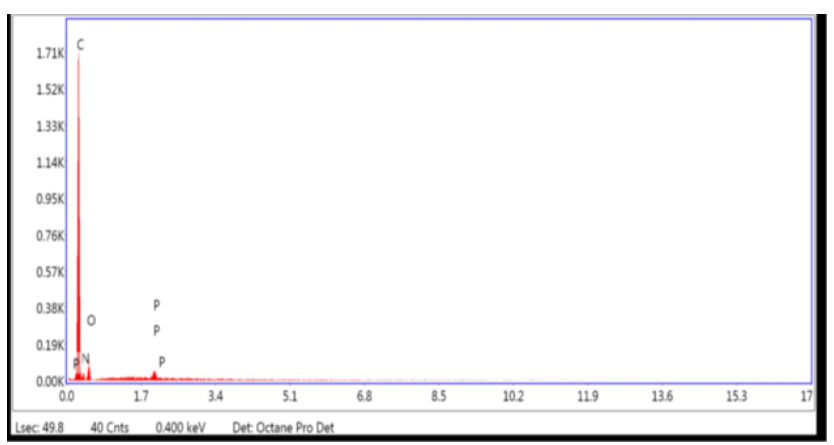

Şekil 7. T1-PA-DSM'ın SEM-EDS grafiği

Tablo 8. T1-PA-DSM'ın atom miktarları

\begin{tabular}{lll}
\hline Element & \% Ă̆ırlık & \% Atomik \\
\hline $\mathrm{C}$ & 69,97 & 74,42 \\
\hline $\mathrm{N}$ & 16,42 & 14,98 \\
\hline $\mathrm{O}$ & 12,95 & 10,34 \\
\hline $\mathrm{P}$ & 0,66 & 0,27 \\
\hline
\end{tabular}




\subsection{Membranların FTIR spektrumları}

Hazırlanan DSM'ların FTIR spektrumları da immobilizasyon ișlemleri sonucu destek tabakaları üzerindeki taşıyıcıların varlığını doğrulamaya katkı açısından alınmış ve aşağıda spektrumları verilmiş̦tir. Şekil 8'de orijinal poliamit ve T1-PA-DSM'ın FT-IR spektrumları birlikte gösterilmiştir. Saf poliamitin $3325 \mathrm{~cm}^{-1}$ de gözlenen ve yapıdaki $\mathrm{N}-\mathrm{H}$ bağına ait gerilme titreşimlerinden kaynaklanan bandı, TOPO taşıyıcısının yapıya eklenmesi sonucu biraz daha șiddetlenmiș ve $3309 \mathrm{~cm}^{-1}$ 'e kaymıștır. $\mathrm{v}(\mathrm{N}-\mathrm{H})$ 'deki bu kayma, poliamit yapısına TOPO taşıyıcısının bağlandığını desteklemektedir.

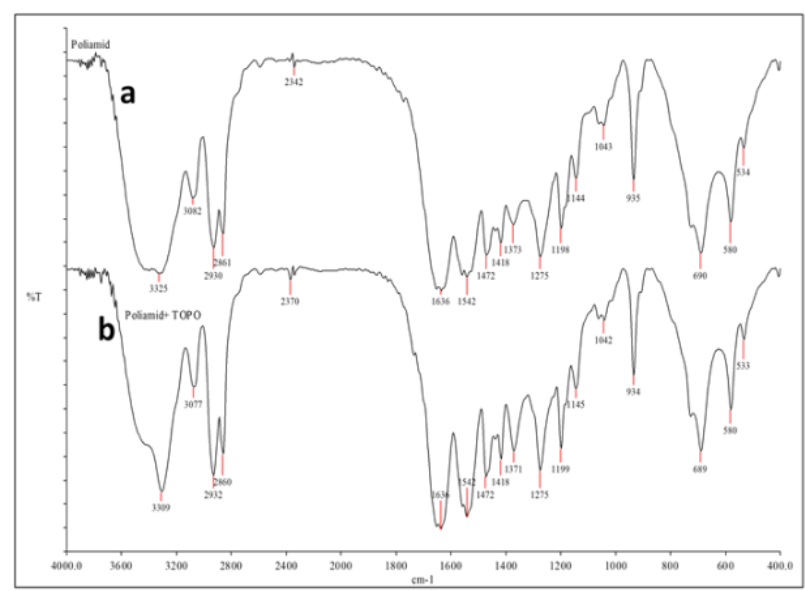

Şekil 8. FT-IR spektrumları (a) Orijinal poliamit membran (b) T1-PA-DSM membran

Şekil 9'da orijinal hidrofob PVDF ve T2-HB-DSM'ın FT-IR spektrumları birlikte gösterilmiștir. FT-IR spektrumları incelendiğinde, hidrofob PVDF destek tabakasına BKOF molekülünün yapıya eklenmesi ile birlikte $1636 \mathrm{~cm}^{-1}$ deki bandın şiddetlendiği gözlenmiştir. $\mathrm{Bu}$ bölgedeki bant $(U(\mathrm{C}=\mathrm{O}))$, BKOF grubu için karakteristiktir ve $1636 \mathrm{~cm}^{-1}$ 'deki bandın şiddetlenmesi, yapıya BKOF grubunun bağlanmasını desteklemektedir [17]. Ayrıca hidrofobik PVDF destek tabakasina BKOF molekülünün bağlanmasından dolayı $2929 \mathrm{~cm}^{-1}$ de oksim grubuna ait $\mathrm{C}$ - $\mathrm{H}$ gerilme titreşimi gözlenmiştir.

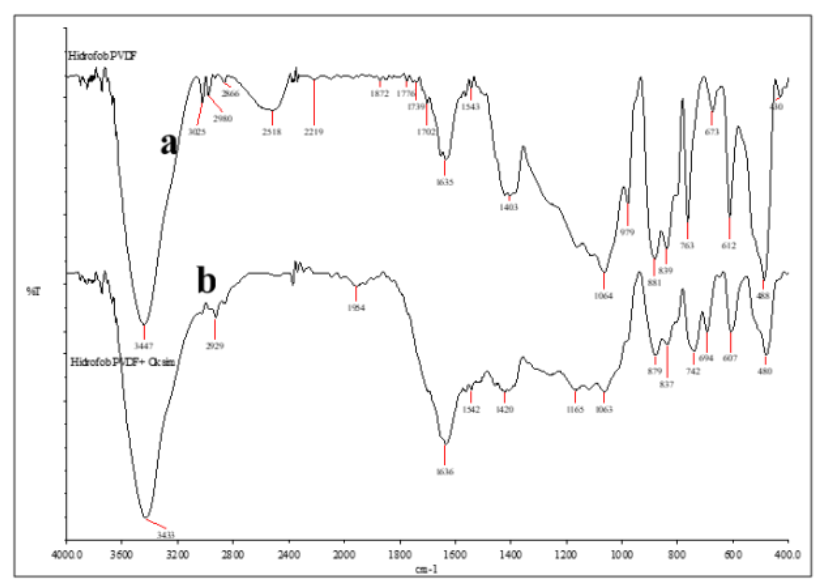

Şekil 9. FT-IR spektrumları (a) orijinal Hidrofob PVDF membran (b) T2-HB-DSM membran

\subsection{Membranların AFM görüntüleri}

Hazırlanan destekli sıvı membranların ve kullanılan destek tabakalarının AFM görüntüleri Şekil 10'da verilmiştir.
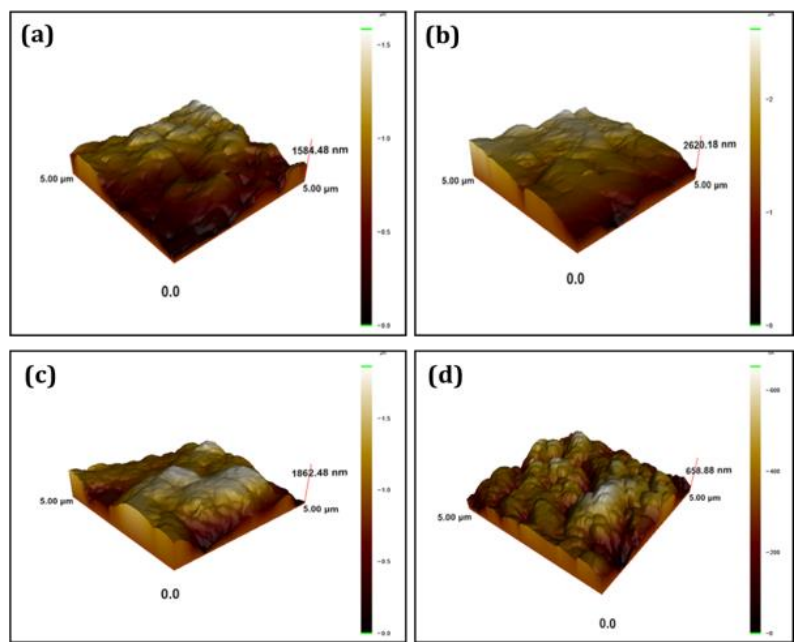

Şekil 10. AFM görüntüleri a) Orijinal Poliamit membran, (b) T1-PA-DSM (c) Orijinal Hidrofob PVDF membran, (d) T2-HB-DSM

AFM görüntülerinden de görüleceği gibi orijinal destek tabakaları ve taşıyıcı içeren destek tabakalarından olușan membranların yüzey yapıları birbirlerinden oldukça farklıdır. Membranların AFM ile karakterizasyonu sonucu gözlemlenen bu farklılıklar taşıyıcı maddenin destek tabasına tutunduğunu ve destek tabakasının yüzey morfolojisini değiștirdiğini göstermektedir.

\subsection{T2-HB-DSM Membranın TGA grafiği}

Şekil 11'de orijinal hidrofob PVDF destek tabakası ve T2-HB-DSM'ın TGA eğrileri aynı şekil üzerinde verilmiştir. T2 taşıyıcısı olan BKOF bileşiği laboratuvar ortamında sentezlenmiş ve ilk defa bu çalışmada kullanılan bir ligand olduğu için sadece bu bileşik için TGA çalışması yapılmıştır.

Hazırlanan orijinal hidrofob PVDF ve T2-HB-DSM'ın termogravimetrik analizleri, $20-900^{\circ} \mathrm{C}$ arasında ve azot atmosferi altında gerçekleștirilerek termogravimetrik analiz diyagramları elde edilmiş ve Șekil 11'de karșılaștırmalı olarak verilmiștir

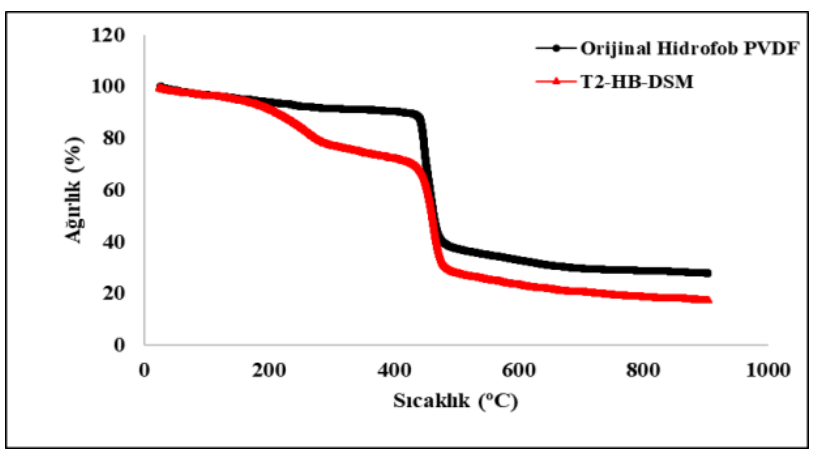

Şekil 11. TGA grafiği; siyah: Orijinal hidrofob PVDF membran, kırmızl: T2-HB-DSM 
Orijinal hidrofob PVDF destek tabakasının termogravimetrik analiz diyagramı incelendiğinde malzemenin üç basamak üzerinden bozunduğu belirlenmiştir. İlk bozunma basamağı $20-420^{\circ} \mathrm{C}$ sıcaklık aralığında tahmini \%10'luk kütle kaybı ile gerçekleşmiştir. $\quad 420-450^{\circ} \mathrm{C}$ arasında ise yaklaşık $\% 50$ ile malzemeye ait en yüksek kütle kaybı meydana gelmiştir. Hidrofob PVDF'nin $450^{\circ} \mathrm{C}^{\prime} \mathrm{de}$ başlayan üçüncü kütle kaybı adımının ise sıcaklığın $900^{\circ} \mathrm{C}^{\prime}$ ye ulaşmasına rağmen devam ettiği gözlenmiştir.

T2-HB-DSM' in termal bozunması ise dört basamakta gerçekleşmiştir. İlk basamak olan $20-250^{\circ} \mathrm{C}$ sıcaklık aralığında tahmini \%25 'lik bir kütle kaybı ile oksim molekülünün yapısında bulunan bifenil, karbonil, oksim ve amin gruplarının kaybı görülmüștür. İkinci basamakta ise $250-420^{\circ} \mathrm{C}$ sıcaklık aralığında tahmini \%5 'lik bir kütle kaybı ile furfuril grubunun ayrıldığı düşünülmektedir. $\mathrm{Bu}$ aşamada oksim molekülü sıcaklığın etkisiyle yapıdan ayrıldığı için termogramın bundan sonraki kısmı, orijinal hidrofob PVDF'nin termogramıyla benzerlik göstermektedir. Üçüncü bozunma basamağı orijinal hidrofob PVDF destek tabakasında da görüldüğü üzere $420-450^{\circ} \mathrm{C}$ aralığında yaklaşık \%45 'lik kütle kaybı ile gerçekleşmiştir. Termal bozunmanın son adımı ise $450^{\circ} \mathrm{C}$ 'de başlamış olup sıcaklığın $900^{\circ} \mathrm{C}$ 'a ulaşmasına rağmen bozunmanın devam ettiği görülmüştür.

Her iki membranın termogramı karşılaștırmalı olarak incelendiğinde, $420^{\circ} \mathrm{C}$ 'den önce gözlenen farklı bozunma basamakları, orijinal hidrofob PVDF destek tabakasına BKOF molekülünün bağlandığını ve sıcaklık artışının etkisiyle $420^{\circ}$ C'ye kadar iki basamakta yapıdan ayrıldığını ifade etmektedir.

\subsection{Destekli sıvı membranların Donnan Diyaliz deneyleri}

Nikel iyonu konsantrasyon değişimini gözlemlemek amacıyla farklı konsantrasyonlarda 3 saatlik donnan diyaliz deneyleri T2-HB-DSM'ı kullanılarak yapılmıştır. Besleme fazında; $1 \times 10^{-1} \mathrm{M}, 1 \times 10^{-2} \mathrm{M}$, $1 \times 10^{-3} \mathrm{M}$ olmak üzere 3 farkl konsantrasyonda $\mathrm{NiCl}_{2} \cdot 6 \mathrm{H}_{2} \mathrm{O}$ çözeltisi ve alıcı faz olarak $1 \times 10^{-1} \mathrm{M} \mathrm{HCl}$ çözeltisi kullanılmıştır. Membranlar ile yapılan 3 saatlik donnan diyaliz deneyleri sonucunda 3 farklı konsantrasyon için süreye karşı taşınan $\mathrm{Ni}(\mathrm{II})$ iyonu konsantrasyon grafiği çizilmiş ve Şekil 12'de verilmiștir.

Demir iyonu konsantrasyon değişimini gözlemlemek amaciyla farklı konsantrasyonlarda 3 saatlik donnan diyaliz deneyleri de T1-PA-DSM'ı kullanılarak yapılmıştır. Besleme fazında; $1 \times 10^{-1} \mathrm{M}, 1 \times 10^{-2} \mathrm{M}$, $1 \times 10^{-3} \mathrm{M}$ olmak üzere 3 farkl konsantrasyonda $\mathrm{Fe}\left(\mathrm{NO}_{3}\right)_{3} .9 \mathrm{H}_{2} \mathrm{O}$ çözeltisi ve alıcı faz olarak $1 \times 10^{-1} \mathrm{M}$ $\mathrm{HNO}_{3}$ çözeltisi kullanılmıştır. Membranlar ile yapılan 3 saatlik donnan diyaliz deneyleri sonucunda 3 farklı

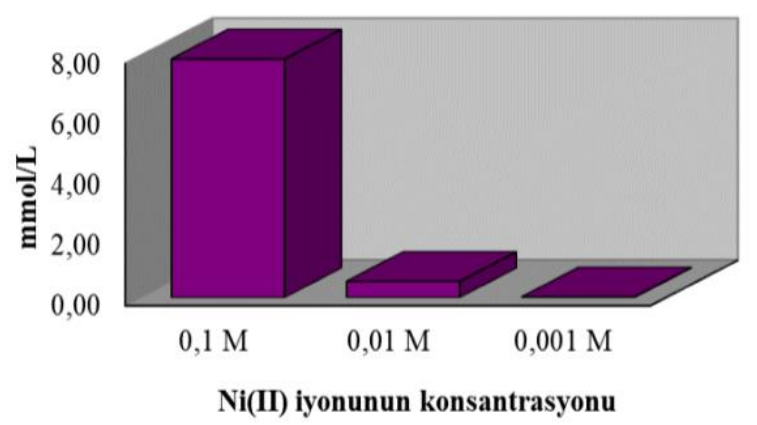

Şekil 12. T2-HB-DSM ile farklı besleme fazı konsantrasyonlarında alıcl fazdaki Ni(II) iyonu konsantrasyon değişimi

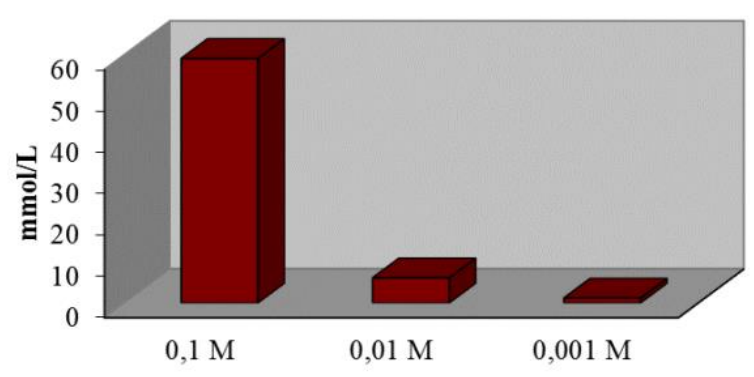

Fe(III) iyonunun konsantrasyonu

Şekil 13. T1-PA-DSM ile farklı besleme fazı konsantrasyonlarında alıcı fazdaki Fe(III) iyonu konsantrasyon değişimi

konsantrasyon için süreye karşı taşınan Fe(III) iyonu konsantrasyon grafiği çizilmiş ve Şekil 13'de verilmiştir.

Hazırlanan membranlar ile besleme fazında farklı konsantrasyonlarda yapılan donnan diyaliz deneyleri sonucunda, konsantrasyon artışının Fe(III) ve Ni(II) iyonlarının taşınımını artırdığı tespit edilmiştir.

\section{Tartışma ve Sonuç}

-Farklı fonksiyonel gruplara sahip biri ticari diğeri de laboratuvar ortamında sentezlenmiş taşıyıcılar kullanılarak T1-PA-DSM ve T2-HB-DSM şeklinde isimlendirilen destekli sıv membranlar hazırlanmıştır.

-Hazırlanan destekli sıvı membranlar SEM, SEM-EDS, AFM, FT-IR ve TGA teknikleri kullanılarak karakterize edilmiştir. Karakterizasyon sonucu elde edilen morfolojik ve spektroskopik veriler hazırlanan DSM'lerin yeni tür membranlar olduğunu ve immobilizasyon işleminin başarılı olduğunu onaylamaktadır.

-Hazırlanan DSM'lerin sulu çözelti ortamından metal uzaklaştırma performasları, Donnan diyaliz metodu kullanılarak $\mathrm{Ni}(\mathrm{II})$ ve Fe(III) iyonları için incelenmiş ve metallerin $1.0 \times 10^{-1} \mathrm{M}$ konsantrasyonda daha yüksek taşıma değerlerine ulaştığı tespit edilmiştir. 


\section{Teşekkür}

4760-YL1-16 No`lu proje ile Yüksek Lisans tezini maddi olarak destekleyen Süleyman Demirel Üniversitesi Bilimsel Araştırma Projeleri Yönetim Birimi Başkanlığı'na teşekkür ederiz.

\section{Kaynakça}

[1] Chrisstoffels, L.A.J., de Jong, F., Reinhoudt, D.N. 1996. Mechanistic Studies of Carrier-Mediated Transport Through Supported Liquid Membranes. ss 18-56. Bartsch, R.A., Douglas Way, J., ed. 1996. Chemical Separations with Liquid Membranes. American Chemical Society, Washington, 422s.

[2] Mulder, M. 1998. Liquid Membranes. ss 340-347. Basic Principles of Membrane Technology, Kluwer Academic Publishers, The Netherlands, $576 \mathrm{~s}$.

[3] Strathmann, H. 1988. Synthetic Membranes and Their Preparation. ss 29-38. Porter, M.C. 1988. Handbook of Industrial Membrane Technology, Noyes Publications, USA, 604s.

[4] Chakrabarty, K., Saha, P., Ghoshal, A.K. 2010. Simultaneous Separation of Mercury and Lignosulfanate from Aqueous Solution Using Supported Liquid Membrane. Journal of Membrane Sciences, 346, 37-44.

[5] Resina, M., Macanás, J., de Gyves, J., Muñoz, M. 2006. Zn(II), Cd(II) and Cu(II) Separation Through Organic-Inorganic Hybrid Membranes Containing Di-(2-ethylhexyl) Phosphoric Acid or Di-(2-ethylhexyl) Dithiophosphoric Acid as a Carrier. Journal of Membrane Sciences, 268, 5764.

[6] Kedarin, C.S., Pandit, S.S., Gandhi, P.M. 2013. Separation by Competitive Transport of Uranium(VI) and Thorium(IV) Nitrates Across Supported Renewable Liquid Membrane Containing Trioctylphosphine Oxide as Metal Carrier. Journal of Membrane Science, 430, 188195.

[7] Ho, W. S., Sirkar, K. K. (Eds.) 1992. Membrane Handbook, Chapman\&Hall, New York, 954s.

[8] Cooper, C.A., Lin, Y.S., Gonzalez, M. 2004. Separation Properties of Surface Modified Silica Supported Liquid Membranes for Divalent Metal Removal/Recovery. Journal of Membrane Science, 229, 11-25.
[9] Kaya, A., Kutlu, T., Hol, A., Surucu, A., Alpoguz, A.K. 2014. Transport of $\mathrm{Pb}(\mathrm{II})$ by Supported Liquid Membrane Containing p-tert-butyl Calix[4]amine Derivative as Carrier. Desalination and Water Treatment, 52 (16-18), 3219-3225.

[10] Kır, E., Yalimli, S., Kurtulmus, S., Aydin, A., Yılmaz, H. 2015. Facilitated Transport of Ni(II) Through Supported Liquid Membranes Containing Dithiophosphonates as Ion Carrier. Phosphorus, Sulfur, and Silicon, 190, 1-13.

[11] Zidi, C., Tayeb, R., Dhahbi, M. 2011. Extraction of Phenol from Aqueous Solutions by Means of Supported Liquid Membrane (MLS) Containing Tri-n-octyl Phosphine Oxide (TOPO). Journal of Hazardous Materials, 194, 62-68.

[12] Raut, D.R., Mohapatra, P.K., Ansari, S.A., Sarkar, A., Manchanda V.K. 2008. Selective Transport of Radio-Cesium by Supported Liquid Membranes Containing Calix[4]crown-6 Ligands as the Mobile Carrier. Desalination, 232, 262-271.

[13] Altınel, E. 2006. Manganese(III) Acetate Mediated Regeneration of Carbonyl Compounds from Oximes. Middle East Technical University, The Graduate Scholl of Natural and Applied Sciences, Master of Science Thesis, 53s, Ankara.

[14] Kurtoğlu, M., Serin, S., 2006. Oksimler; Sentezi, Reaksiyonları ve Metal Kompleksleri. Kahramanmaraş Sütçü İmam Üniversitesi Fen ve Mühendislik Dergisi, 9 (2), 25-32.

[15] Hichour, M., Persin, F., Sandeaux, J., Gavach, C. 2000. Fluoride Removal from Waters by Donnan Dialysis. Separation and Purification Technology, 18(1), 1-11.

[16] Akretche, D.E., Kergjoudj, H. 2000. Donnan Dialysis of Copper, Gold and Silver Cyanides with Various Exchange Membranes. Talanta, 51 (2), 281-289.

[17] Dede, B., Karipcin, F., Arabali, F., Cengiz, M. 2010. Synthesis, Structure, and Solvent-Extraction Properties of Tridentate Oxime Ligands and Their Cobalt(II), Nickel(II), Copper(II), Zinc(II) Complexes. Chemical Papers, 64 (1), 25-33.

[18] Meddour, L., Didi, M.A. 2007. Purification of Trin-Octyl Phosphine Oxide by Extraction and Precipitation. Extraction of Zn, Mo and Fe in Acid Medium. Scientific Study \& Research, 8 (3), 269280. 